\title{
Thymidylate synthase expression pattern, expression level and single nucleotide polymorphism are predictors for disease-free survival in patients of colorectal cancer treated with 5-fluorouracil
}

\author{
MARÍA-ENCARNACIÓN FERNÁNDEZ-CONTRERAS ${ }^{1}$, SANDRA SÁNCHEZ-PRUDENCIO², \\ JOSÉ-JAVIER SÁNCHEZ-HERNÁNDEZ ${ }^{3}$, MARÍA-LUISA GARCÍA DE PAREDES ${ }^{4}$, \\ JAVIER P. GISBERT ${ }^{2}$, PEDRO RODA-NAVARRO ${ }^{5}$ and CARLOS GAMALLO ${ }^{1}$
}

\begin{abstract}
Departments of ${ }^{1}$ Pathology and ${ }^{2}$ Gastroenterology, Hospital Universitario de la Princesa; ${ }^{3}$ Department of Biostatistics and Epidemiology, School of Medicine; ${ }^{4}$ Department of Oncology, Hospital Universitario Ramón y Cajal, Universidad Autónoma de Madrid, Spain; ${ }^{5}$ Department of Pathology, University of Cambridge, UK
\end{abstract}

Received November 30, 2005; Accepted January 12, 2006

\begin{abstract}
Several variables associated to thymidylate synthase (TS), the biological target of 5-fluorouracil (5FU) have been studied for their possible role as predictors of the clinical outcome and response to chemotherapy in colorectal cancer (CRC) patients. The level of protein expression and the number of variable tandem-repeats of a 28 -bp sequence within the gene promoter have been proposed as predictive and/or prognostic factors with variable agreement, while consensus seems to be achieved with respect to the value of a single nucleotide polymorphism (SNP) described within this same region. More recently, an association between TS expression pattern and survival has been disclosed. Paraffin-embedded sections from 140 CRC patients were analyzed by immunohistochemistry (Mab TS106) for TS levels and expression pattern. Also, VNTR and SNP were determined by polymerase-chain reaction (PCR) and restriction-length-fragment polymorphism (RFLP) in 123 and 112 patients, respectively. Cytoplasmic expression pattern tended to be associated to $\mathrm{C}$ SNP ( $p=0.06)$. Low TS expression levels, cytoplasmic expression pattern and C SNP arose as variables associated to longer progression-free survival (PFS) in patients treated with 5FU. Accordingly, patients having at least two favourable or unfavourable variables were classified respectively as 'low risk' and 'high risk', the former showing significantly longer PFS ( $p=0.0299$ ). The possibility for designing a selection method for subsequent therapies is suggested on the basis of a probable combined effect of the above mentioned
\end{abstract}

Correspondence to: Professor Carlos Gamallo, Servicio de Anatomía Patológica, Hospital Universitario de la Princesa, 2a Planta, C/Diego de León 62, 28006 Madrid, Spain

E-mail: cgamallo.hlpr@salud.madrid.org

Key words: thymidylate synthase, DNA polymorphism, colorectal cancer, immunostaining pattern, prognosis parameters but further studies in larger populations are needed to confirm these results.

\section{Introduction}

As thymidylate synthase (TS) is the biological target of 5fluorouracil (5FU) and related drugs, which constitute the treatment of choice for colorectal cancer (CRC) and many other tumours, a variety of features related to this enzyme have been studied as possible predictors for the clinical outcome of CRC patients. High intratumoral expression of thymidylate synthase (TS) has been widely reported as a factor of poor prognosis in patients with advanced colorectal cancer (CRC) (1), but such association is unclear in some studies (2-6). More recently, the intracellular expression pattern [i.e. cytoplasmic or mixed (nuclear and cytoplasmic)] has been postulated as prognostic in patients treated with $5 \mathrm{FU}(7)$, but further studies to confirm this are lacking.

Gene polymorphisms have been disclosed within the TS gene promoter. A variable number of a tandem repeat (VNTR) sequence of 28 bp has been identified in the 5'untranslated region (5'-UTR) and alleles containing two and three repeats have been found $(8,9)$ and more rarely, four, five and nine repeats have also been encountered in Asian and African populations (10-13). The frequencies of the different VNTR polymorphisms vary with race (9-13). An association has been proposed between TS VNTR polymorphism and levels of protein expression, probably throughout an effect on the translational efficiency of the gene (14), and/or enzyme activity, and, on the other hand, many studies propose VNTR genotype as marker for survival and/or response to 5FU treatment. However, results are also conflicting and, while high TS levels, poorer survival, and low response to $5 \mathrm{FU}$ have been associated to homozygous genotype for triple repeats $(3 R / 3 R)(8,14-16)$, heterozygous 2R/3R CRC patients with liver metastasis have shown higher TS activity than homozygous $3 \mathrm{R} / 3 \mathrm{R}$ or $2 \mathrm{R} / 2 \mathrm{R}$ ones in other studies (17), survival being significantly longer for 
Table I. Characteristics of the studied patients. ${ }^{a}$

\begin{tabular}{ll}
\hline Age $(\mathrm{x} \pm \mathrm{SD})$ & $66.6 \pm 11.0$ \\
Median OS & 82 months $(76.2-87.2)$ \\
Median PFS & 41 months $(20.9-61)$ \\
Gender & \\
$\quad$ Male & $71(47.7)$ \\
Female & $78(52.3)$ \\
Dukes' stage & \\
$\mathrm{B}_{2}$ & $70(47)$ \\
$\mathrm{C}$ & $57(38.3)$ \\
$\mathrm{D}$ & $22(14.8)$ \\
Tumour location & \\
Right & $37(25.2)$ \\
Left & $63(42.3)$ \\
Rectum & $38(26.1)$ \\
Transverse & $11(7.2)$ \\
\hline
\end{tabular}

${ }^{\mathrm{a}} \mathrm{X}$, mean; SD, standard deviation.

homozygous $3 \mathrm{R} / 3 \mathrm{R}$ patients $(17,18)$. A single nucleotide polymorphism (SNP) consisting on a $\mathrm{G} \rightarrow \mathrm{C}$ substitution in a HaelII recognition site within the second 28-bp repeat has also been described $(19,20)$ and proposed as a prognostic factor. Functional studies have related this SNP to TS expression (19-21) and, accordingly, patients harbouring the $\mathrm{G}$ allele in either homozygosis or heterozygosis have been classified as 'high expressors' while those homozygous for the $\mathrm{C}$ allele (i.e., $2 \mathrm{R} / 2 \mathrm{R}$, who always carry the $\mathrm{CGCC}$ sequence within the second repeat, as well as those with $2 \mathrm{R} / 3 \mathrm{C}$, and $3 \mathrm{C} / 3 \mathrm{C}$ genotypes) have been considered as 'low expressors', with longer survival and/or time to relapse (19-22).

In order to elucidate the possible separate or combined role of all these factors on the disease progression of CRC patients treated with 5FU, TS VNTR and SNP genotypes were investigated, together with protein levels and expression pattern as determined by IHC.

\section{Patients and methods}

Patients and samples. A total number of 149 patients diagnosed with colorectal carcinoma between 1993 and 2002 were studied. One hundred and one of them had undergone adjuvant chemotherapy treatment with $5 \mathrm{FU}$ after surgical resection of their tumour; 24 did not receive adjuvant treatment and seven received $5 \mathrm{FU}$ as palliative therapy. The remaining 17 were lost during the course of the study. The mean follow-up period was $39.4 \pm 22.4$ months.

Samples consisted of paraffin-embedded specimens of primary tumours and normal adjacent mucosa, collected from the Archives of the Pathology Department of the University Hospital of La Princesa (Universidad Autónoma, Madrid, Spain). Data processing was carried out so that patients' confidentiality was warranted.
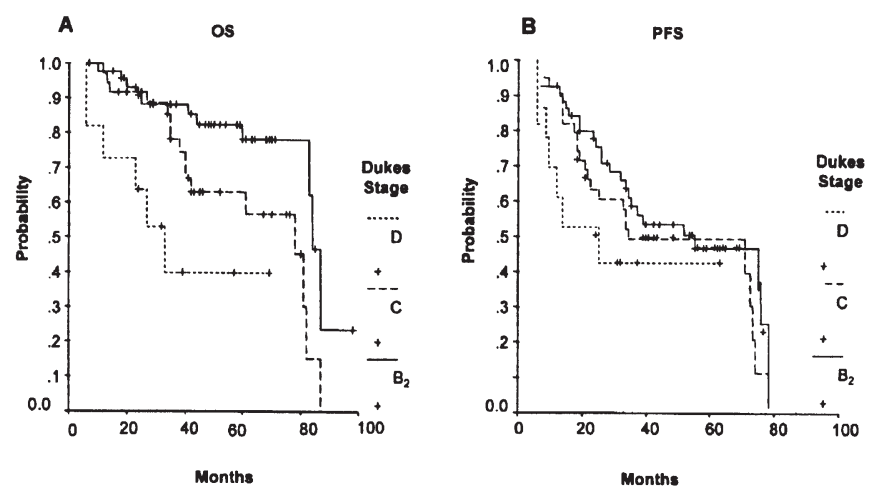

Figure 1. Overall and progression-free survival related to Dukes stage. (A) OS was significantly shorter for patients with tumours classified as D stage $(\mathrm{p}=0.010$; log-rank). (B) A similar trend was observed for PFS ( $\mathrm{p}=0.1169$, log-rank; 0.0315, Breslow; and 0.0649, Tarone-Ware).

\section{TS promoter polymorphism}

DNA extraction. Genomic DNA was extracted from paraffinembedded tissue. Tissue sections were boiled at $100^{\circ} \mathrm{C}$ for 10 min in Tris $50 \mathrm{mM}$ and incubated at $55^{\circ} \mathrm{C}$ for $48 \mathrm{~h}$ in proteinase $\mathrm{K}(400 \mu \mathrm{g} / \mathrm{ml})$. After heat-inactivation, the cellular debris was pelleted by centrifugation, and the supernatant transferred to a clean tube.

VNTR polymorphism. Polymerase-chain reaction (PCR) was performed using specific primers described by Kawakami et al (20). Briefly, 100-500 ng of DNA were amplified in a final reaction volume of $50 \mu \mathrm{l}$ containing $25 \mathrm{pmol}$ of each primer, $1.25 \mathrm{U}$ of Biotools DNA polymerase (Biotools B\&M Labs., S.A. Madrid, Spain), $1 \mathrm{X}$ reaction buffer, $2 \mathrm{mM} \mathrm{MgCl}_{2}, 200$ $\mu \mathrm{M}$ dNTPs and $10 \%$ dimethyl sulfoxide (DMSO). Forward and reverse specific primers were provided by Metabion International AG. (Martinsried, Germany). The remaining PCR reagents were supplied by Biotools B\&M Labs.

PCR was carried out in a GeneAmp PCR system 2700 (Applied Biosystems, Foster City, CA, USA). An initial denaturation step of $94^{\circ} \mathrm{C}$ for 10 min was followed by 43 cycles of denaturation $\left(94^{\circ} \mathrm{C}\right.$ for $\left.1 \mathrm{~min}\right)$, annealing $\left(60^{\circ} \mathrm{C}\right.$ for $\left.1 \mathrm{~min}\right)$ and primer extension $\left(72^{\circ} \mathrm{C}\right.$ for $\left.2 \mathrm{~min}\right)$, and a final elongation step $\left(72^{\circ} \mathrm{C}\right.$ for $\left.7 \mathrm{~min}\right)$. Amplification products of $112 \mathrm{bp}$ (homozygous $2 \mathrm{R} / 2 \mathrm{R}$ ), $140 \mathrm{bp}$ (homozygous $3 \mathrm{R} / 3 \mathrm{R}$ ) or both (heterozygous $2 \mathrm{R} / 3 \mathrm{R}$ ) were apparent upon $2 \%$ agarose gel electrophoresis visualization.

SNP. Single nucleotide polymorphism was determined by RFLP analysis as described previously (20). PCR products $(10 \mu \mathrm{l})$ were digested for $2 \mathrm{~h}$ at $37^{\circ} \mathrm{C}$ with HaelII restriction endonuclease (Takara Bio Inc. Otsu, Shiga, Japan) and the fragments were electrophoresed on $4 \%$ high resolution agarose (Conda Laboratories, Madrid, Spain).

Microsatellite instability (MSI). Microsatellite instability was determined by specific PCR for BAT25 and BAT26 loci as described previously (23).

IHC evaluation of TS. TS levels and expression patterns were determined as described previously (7), using the TS106 monoclonal antibody (Chemicon International, Inc. Temecula, CA). 
Table II. VNTR polymorphism of the TS promoter. ${ }^{\mathrm{a}}$

\begin{tabular}{|c|c|c|c|c|c|}
\hline & \multirow[t]{2}{*}{$\mathbf{N}$} & \multicolumn{3}{|c|}{ TS genotype } & \multirow[t]{2}{*}{ p-value } \\
\hline & & $2 \mathrm{R} / 2 \mathrm{R}$ & $3 R / 3 R$ & $2 R / 3 R$ & \\
\hline Age $(x \pm S D)$ & $66.7 \pm 11.1$ & $67.1 \pm 11.3$ & $66 \pm 11.1$ & $66.6 \pm 11.1$ & 0.9 \\
\hline \multicolumn{6}{|l|}{ Gender } \\
\hline Male & 51 & $9(17.7)$ & $9(17.7)$ & $33(64.7)$ & 0.2 \\
\hline Female & 67 & $14(20.9)$ & $20(29.9)$ & $33(49.3)$ & \\
\hline \multicolumn{6}{|l|}{ Dukes stage } \\
\hline $\mathrm{B}_{2}$ & 56 & $14(25)$ & $13(23.2)$ & $29(51.8)$ & 0.7 \\
\hline $\mathrm{C}$ & 41 & $6(14.6)$ & $10(24.4)$ & $25(61.7)$ & \\
\hline $\mathrm{D}$ & 21 & $3(14.3)$ & $6(28.6)$ & $12(57.1)$ & \\
\hline \multicolumn{6}{|c|}{ TS expression level } \\
\hline Weak & 60 & $14(23.3)$ & $12(20)$ & $34(56.7)$ & 0.5 \\
\hline Strong & 49 & $8(16.3)$ & $14(28.6)$ & $27(55.1)$ & \\
\hline \multicolumn{6}{|c|}{ TS expression pattern } \\
\hline Cytoplasmic & 33 & $9(27.2)$ & $7(21.2)$ & $17(51.5)$ & 0.5 \\
\hline Nuclear & 65 & $10(15.4)$ & $18(27.7)$ & $37(56.9)$ & \\
\hline \multicolumn{6}{|l|}{$\operatorname{MSI}(B A T 25)$} \\
\hline No & 89 & $15(16.9)$ & $22(24.7)$ & $52(58.4)$ & 0.2 \\
\hline Yes & 10 & $3(30)$ & $4(40)$ & $3(30)$ & \\
\hline \multicolumn{6}{|l|}{ MSI (BAT26) } \\
\hline No & 91 & $15(16.5)$ & $22(24.2)$ & $54(59.3)$ & 0.2 \\
\hline Yes & 10 & $3(30)$ & $4(40)$ & $3(30)$ & \\
\hline
\end{tabular}

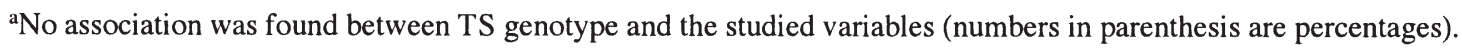

Samples were evaluated by visual examination and assigned a score for intensity of staining in areas where this was stronger: 0 , no staining; 1, low; 2, moderate; and 3, high. For correlation purposes, TS expression was differentiated into 'weak' (0-1) and 'strong' (2-3). Also, the immunostaining pattern of expression was classified as 'cytoplasmic' or 'nuclear' (nuclear with or without cytoplasmic expression). Visual assessment of TS level and immunostaining patterns was performed separately by two pathologists.

Statistical analysis. Comparison of qualitative and quantitative variables was carried out respectively by $\chi^{2}$ and nonparametric Kruskal-Wallis tests. Quantitative variables are expressed by mean values \pm standard deviation (SD).

Overall and progression-free survival were studied only in patients treated with 5FU with an overall survival (OS) of 6 months or longer, this variable being defined as the period from primary surgery until death of the patient of CRC. Death from unrelated causes was considered as a censoring event. Progression-free survival (PFS) was defined as the period from the end of the primary therapy to the first evidence of disease progression. Both parameters were estimated according to the Kaplan-Meier method (24) and compared using the log-rank, Breslow and Tarone-Ware tests.

Statistical significance was assumed for $p<0.05$. All statistical analyses were performed using the SPSS software, version 8.0 (SPSS Inc., Chicago, IL).

\section{Results}

Demographic and clinicopathological findings. The demographic and clinicopathological features of the studied patients are shown in Table I. The mean age was $66.6 \pm 11.0$ years and there were 71 males and 78 females. The median OS and PFS were respectively 82 months (76.2-87.2) and 41 months (20.9-61).

Some association was observed between Dukes stage and gender $[15 / 22$ patients $(68.2 \%)$ with tumours classified as D were male] but $\mathrm{p}$-values did not reach statistical significant ( $p=0.09$ and 0.07 , respectively; data not shown).

Clinicopathological features and survival. Only Dukes stage was found to be strongly associated with OS ( $p=0.010$, Fig. 1A). Concerning PFS, log-rank p-value did not reach statistical significance $(0.1169)$ but a trend indicating an association between this variable and tumour stage was observed ( $\mathrm{p}=0.0315$, Breslow; $\mathrm{p}=0.0649$, Tarone-Ware) (Fig. 1B).

\section{TS promoter polymorphism}

VNTR. The VNTR polymorphism of 5' UTR of the TS promoter was determined in 123 patients. Twenty-three (18.7\%) were homozygous for the double-repeat (2R) allele (2R/2R genotype), 29 (23.6\%) for $3 R$ allele (3R/3R genotype) and $66(53.7 \%)$ were heterozygous (2R/3R). Homozygous 
Table III. SNP polymorphism of the TS promoter. ${ }^{\mathrm{a}}$

\begin{tabular}{|c|c|c|c|c|c|c|}
\hline & \multicolumn{6}{|c|}{ TS genotype } \\
\hline & $2 R / 2 R$ & $2 \mathrm{R} / 3 \mathrm{G}$ & $2 \mathrm{R} / 3 \mathrm{C}$ & $3 \mathrm{G} / 3 \mathrm{G}$ & $3 G / 3 C$ & $3 \mathrm{C} / 3 \mathrm{C}$ \\
\hline Male & $11(23.4)$ & $19(40.4)$ & $9(19.1)$ & 0 & $6(12.8)$ & $2(4.3)$ \\
\hline Female & $14(21.5)$ & $19(29.2)$ & $12(18.5)$ & $5(7.8)$ & $12(18.5)$ & $3(4.6)$ \\
\hline \multirow[t]{3}{*}{ Total } & $25(22.3)$ & $38(33.9)$ & $21(18.8)$ & $5(4.5)$ & $18(16.1)$ & $5(4.5)$ \\
\hline & & \multicolumn{5}{|c|}{ TS allele } \\
\hline & & $2 \mathrm{R}$ & & $3 G$ & & $3 \mathrm{C}$ \\
\hline Male & & $50(53.2)$ & & $25(26.6)$ & & $19(20.2)$ \\
\hline Female & & $59(45.4)$ & & $41(31.5)$ & & $30(23)$ \\
\hline Total & & $109(48.7)$ & & $66(29.5)$ & & 49 (21.9) \\
\hline
\end{tabular}

${ }^{\mathrm{a} G e n o t y p e}$ and allele distribution (numbers in parenthesis are percentages).
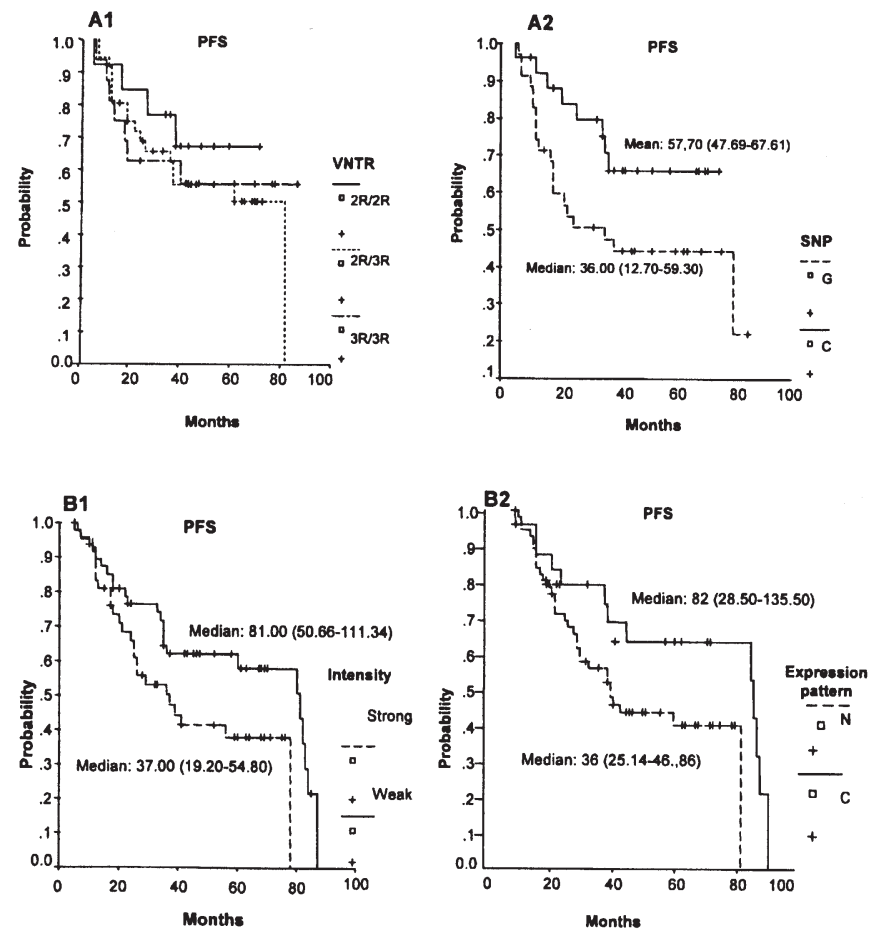

Figure 2. Factors associated to PFS. (A) Gene polymorphism of TS promoter: No association was found with VNTR ( $\mathrm{p}=0.6957, \log$-rank) (A1), but PFS was longer for ' $C$ ' patients $(\mathrm{p}=0.06$, log-rank; 0.04 , Breslow; and 0.05 , Tarone Ware) (A2); (B) TS expression: Low TS levels and cytoplasmic expression pattern were linked with longer PFS $(\mathrm{p}=0.0378$ and 0.0502 , respectively).

tumour tissue with matched heterozygous normal mucosa was found in five patients, who were classified as LOH cases. Due to the small number, they were not included in subsequent analyses relative to VNTR. Table II shows the comparison between VNTR genotype and other studied variables.

VNTR and survival: no association was found between VNTR polymorphism and PFS (Fig. 2A1) or OS (data not shown).
SNP. The SNP within the second tandem repeat was investigated in 112 patients. Sixty-one $(54.5 \%)$ harboured the $3 \mathrm{G}$ allele in either heterozygosis or homozygosis $(2 \mathrm{R} / 3 \mathrm{G}$, $3 \mathrm{G} / 3 \mathrm{G}$, and $3 \mathrm{G} / 3 \mathrm{C}$ genotypes) and were termed as Group $\mathrm{G}$, while $51(45.5 \%$ ) displayed $2 \mathrm{R} / 2 \mathrm{R}, 2 \mathrm{R} / 3 \mathrm{C}$ and $3 \mathrm{C} / 3 \mathrm{C}$ genotypes (Group C). The frequencies of the different TS genotypes and TS alleles are shown in Table III.

The association between SNP and other studied parameters is summarized in Table IV. SNP was found to be connected with MSI $(p=0.01)$ and tended to be related with cytoplasmic IHC expression pattern, though statistical significance was not reached $(\mathrm{p}=0.06)$.

SNP and survival: single nucleotide polymorphism was associated with PFS ( $\mathrm{p}=0.06$, log-rank; 0.04, Breslow; and 0.05, Tarone Ware) (Fig. 2A2).

TS levels and immunostaining pattern. TS expression was assessed in 140 patients. Enzyme levels, revealed by IHC were strong in 63 patients (45\%) and low in 77 (55\%). TS immunostaining pattern was cytoplasmic in 48 patients $(37.8 \%)$ and nuclear in $79(62.2 \%)$. TS levels and expression pattern were found to be strongly correlated $(\mathrm{p}=0.02$, Table V). Thirty-one tumours with cytoplasmic TS expression (64.6\%) showed weak immunostaining while 46 out of 63 tumours with strong expression level (73\%) displayed a nuclear pattern.

TS levels and survival: strong and low TS expression levels were significantly associated to PFS ( $\mathrm{p}=0.04)$, low expression being related to longer time to disease progression (Fig. 2B1).

TS expression pattern and survival: cytoplasmic expression pattern was found to be associated to longer PFS ( $p=0.05$, Fig. 2B2).

MSI. BAT25 and BAT26 loci were analyzed in 106 patients. Instability was detected in 10 cases $(9.6 \%)$.

Risk of CRC. In order to evaluate a possible combined effect of the three parameters found to be independently associated 
Table IV. SNP polymorphism of the TS promoter. ${ }^{\mathrm{a}}$

\begin{tabular}{|c|c|c|c|c|}
\hline & \multirow[t]{2}{*}{$\mathrm{N}$} & \multicolumn{2}{|c|}{ TS genotype } & \multirow[t]{2}{*}{ p-value } \\
\hline & & G & $\mathrm{C}$ & \\
\hline Age $(x \pm S D)$ & $66.9 \pm 11.1$ & $66.9 \pm 11.4$ & $66.9 \pm 10.8$ & 0.9 \\
\hline \multicolumn{5}{|l|}{ Gender } \\
\hline Male & 47 & $25(53.2)$ & $22(46.8)$ & \multirow[t]{2}{*}{0.9} \\
\hline Female & 65 & $36(55.4)$ & $36(44.6)$ & \\
\hline \multicolumn{5}{|l|}{ Dukes stage } \\
\hline $\mathrm{B}_{2}$ & 51 & $24(47.1)$ & $27(52.9)$ & \multirow[t]{3}{*}{0.2} \\
\hline $\mathrm{C}$ & 43 & $24(55.8)$ & $19(44.2)$ & \\
\hline $\mathrm{D}$ & 18 & $13(72.2)$ & $5(27.8)$ & \\
\hline \multicolumn{5}{|c|}{ TS expression level } \\
\hline Weak & 58 & $29(50)$ & $29(50)$ & \multirow[t]{2}{*}{0.6} \\
\hline Strong & 47 & $27(57.5)$ & $20(42.6)$ & \\
\hline \multicolumn{5}{|c|}{ TS expression pattern } \\
\hline Cytoplasmic & 32 & $12(37.5)$ & $20(62.5)$ & \multirow[t]{2}{*}{0.06} \\
\hline Nuclear & 63 & $38(60.3)$ & $25(39.7)$ & \\
\hline \multicolumn{5}{|l|}{ MSI (BAT25) } \\
\hline No & 91 & $56(61.5)$ & $35(38.5)$ & \multirow[t]{2}{*}{0.01} \\
\hline Yes & 9 & $1(11.1)$ & $8(88.9)$ & \\
\hline \multicolumn{5}{|l|}{$\operatorname{MSI}(B A T 26)$} \\
\hline No & 93 & $56(60.2)$ & $37(39.8)$ & \multirow[t]{2}{*}{0.01} \\
\hline Yes & 9 & $1(11.1)$ & $8(88.9)$ & \\
\hline
\end{tabular}

${ }^{a}$ This variable was found to be linked with BAT25 and BAT26 instability and nearly significant association with TS expression pattern was also encountered: tumours displaying cytoplasmic immunostaining pattern tended to be $C(p=0.06)$ and most instable belonged to this group $(\mathrm{p}=0.01)$ (numbers in parenthesis are percentages).

Table V. Thymidylate synthase expression levels and immunostaning pattern were significantly associated $(\mathrm{p}=0.02){ }^{\mathrm{a}}$

\begin{tabular}{llll}
\hline Immunostaining & \multicolumn{2}{c}{ Expression levels } & p-value \\
\cline { 2 - 3 } pattern & Weak & Strong & \\
\hline Cytoplasmic & $31(64.6)$ & $17(35.4)$ & 0.02 \\
Nuclear & $33(41.8)$ & $46(58.2)$ & \\
\hline
\end{tabular}

${ }^{a}$ Cytoplasmic pattern was linked with weak TS levels while most tumours with strong immunostaining displayed nuclear expression (numbers in parenthesis are percentages).

with PFS (TS expression level, TS expression pattern and SNP), patients were classified into two groups for a new survival analysis. Subjects with at least two variables of good prognosis (low IHC intensity, cytoplasmic pattern, C SNP) were defined as low risk patients $(\mathrm{N}=20)$, while those with at least two variables of poor prognosis (high IHC intensity, nuclear pattern, G SNP) were considered as high risk patients $(\mathrm{N}=39)$. Time to progression was significantly longer for the low-risk group [median: 80 months (17.74-142.26) versus 36 months (14.74-57.26); C.I.: 95\%; p=0.0299] (Fig. 3A).

\section{Discussion}

The interest in genetic factors that could be predictive for response to $5 \mathrm{FU}$ treatment is increasing, as new alternatives to this drug are being developed. A number of studies have investigated TS gene promoter polymorphisms as possible markers for response to chemotherapy and, thus, for survival in CRC patients. Homozygosis for double tandem repeats described within the 5'UTR region has been associated to better prognosis, as well to lower TS expression. This latter feature has also been linked with the $\mathrm{G} \rightarrow \mathrm{C}$ substitution characterizing the SNP described within the same gene sequence, which has also been proposed as a predictor of good prognosis.

VNTR. The frequencies of $2 \mathrm{R} / 2 \mathrm{R}, 3 \mathrm{R} / 3 \mathrm{R}$ and $2 \mathrm{R} / 3 \mathrm{R}$ genotypes were $18.7,23.6$ and $53.7 \%$ respectively, which is consistent 

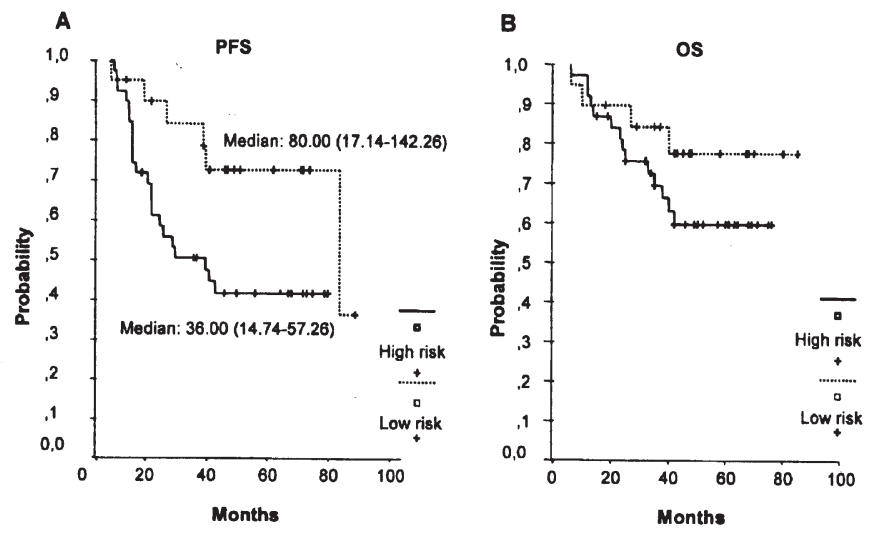

Figure 3. Survival in low risk and high risk patients. Kaplan-Meier analysis revealed significant differences concerning PFS $(\mathrm{p}=0.0299)$ (A). Statistical significance was not reached for OS (B) but a similar plot was observed.

with those reported for Caucasian patients. VNTR frequencies have been found to be race-related and, while $2 \mathrm{R} / 3 \mathrm{R}$ genotype represents $\sim 40-50 \%$ of Caucasian, Black and South-Western Asian populations $(12,17,18,22,25)$, this rate decreases to $\sim 30 \%$ in Japanese, Chinese and Korean patients $(10,11,26)$. Conversely, homozygous $2 \mathrm{R} / 2 \mathrm{R}$ do not reach $10 \%$ in these populations, but rise to $20 \%$ in the former groups. The frequencies of these genotypes are independent from the tissue (tumour or normal) and no differences have been found either between patients and healthy volunteers.

VNTR and survival. We failed to find any association between VNTR genotype and survival, neither individually, nor grouping them $(3 \mathrm{R} / 3 \mathrm{R}$ vs. others nor $2 \mathrm{R} / 2 \mathrm{R}$ vs. others, data not shown) $(18,25,26)$. Neither did we observe any relationship between VNTR polymorphism and toxic reactions (data not shown) as has been suggested $(27,28)$. Previous studies relate VNTR with survival and/or response to chemotherapy, but their results are variable and sometimes conflicting. Homozygous $2 \mathrm{R} / 2 \mathrm{R}$ and heterozygous $2 \mathrm{R} / 3 \mathrm{R}$ patients seem to display similar behaviour, both genotypes have been proposed as markers of good prognosis $(11,29)$ and predictors of tumour down-staging (16); they have been found to be related to lower enzyme activity and longer survival $(14,26)$. However, in other investigations $2 \mathrm{R} / 3 \mathrm{R}$ genotype correlated with higher enzyme activity and has been associated to poorer survival, while $3 \mathrm{R} / 3 \mathrm{R}$ has been related to better response (18) and good prognosis (17). In some studies, the association between VNTR polymorphism and survival showed a trend that did not reach statistical significance $(16,27)$.

Other investigations are consistent with our data, in contrast to the above reviewed results: Tsuji et al concluded also that VNTR is not an effective predictor for 5FU sensitivity (26), this observation being supported, among other results, by the fact that, though genotype frequencies are race-dependent, the five-year survival is similar among different populations. Similar results have been found more recently in patients of gastric cancer by Lee et al (30) also in the Asian population.

SNP. Previous in vitro studies have disclosed that the $\mathrm{G} \rightarrow \mathrm{C}$ substitution at position 12 within the second tandem repeat directly influences TS levels because it disrupts an E-box binding site for upstream regulatory factor (USF-1/USF-2) within each 28-bp repeat, except the last one (19). Thus, the transcriptional activity of the TS gene would not be enhanced by the number of tandem repeats, but for the extra USF Ebox within each one of them. $2 \mathrm{R} / 3 \mathrm{C}$ and $3 \mathrm{C} / 3 \mathrm{C}$ genotypes have shown to induce low protein expression, similar to that observed for $2 \mathrm{R} / 2 \mathrm{R}$, while the presence of the $3 \mathrm{G}$ allele clearly increases enzyme levels (19-21). Accordingly, previous clinical reports have classified patients as 'low expressors' and 'high expressors' $(20,22,27)$.

In our study, TS levels were determined by IHC. Immunostaining intensity showed no association with SNP. Moreover, as further functional analysis to determine protein expression were not performed, the terms 'high' and 'low' expressors were not considered suitable for patient classification in our study and, therefore, these were grouped as ' $G$ ' $(2 R / 3 G, 3 G / 3 C$, $3 \mathrm{G} / 3 \mathrm{G})$ or ' $\mathrm{C}$ ' $(2 \mathrm{R} / 2 \mathrm{R}, 2 \mathrm{R} / 3 \mathrm{C}, 3 \mathrm{C} / 3 \mathrm{C})$. Thus, 51 patients (45.4\%) were stated as $C$ and $61(54.5 \%)$ as $\mathrm{G}$.

In contrast to VNTR polymorphism, the reported rates of each genotype in the reviewed literature are rather heterogeneous, perhaps because they determine six subgroups including small numbers of patients $(19,20,22,27)$. When the rates of our $\mathrm{G}$ and $\mathrm{C}$ patients were compared with those of high and low expressors reported by others differences were not apparent, both groups ranging $\sim 50 \%$ in most cases. An exception should be made with the Chinese and Japanese populations $(19,20)$, where $>60 \%$ of patients are harbouring the $3 \mathrm{G}$ allele. However, these differences are probably due to the previously mentioned race variability of VNTR polymorphism rather than to SNP, for $2 \mathrm{R} / 2 \mathrm{R}$ patients, which are a subset within low expressors, accounting for only 2$8 \%$ in Asian populations.

No association was found between SNP and age, gender, Dukes stage, tumour location or immunostaining intensity, but a nearly significant relationship was found with respect to expression pattern $(\mathrm{p}=0.06)$, most patients with nuclear expression were $\mathrm{G}(38,60.3 \%)$ while those with cytoplasmic pattern were mainly $\mathrm{C}(20,62.5 \%)$.

$B A T 25$ and $B A T 26$ instability was present in nine patients, eight $(88.9 \%)$ of them being $C(p=0.01)$. MSI has also been linked with good prognosis in advanced stages of sporadic CRC (23,31-33) although variable results have been reported $(34,35)$. Nevertheless, the relationship with SNP is probably coincidental, although the latter could explain the different data about the prognostic value of MSI found in the reviewed literature.

SNP and survival. In our study, SNP did not show any effect on OS, but G patients displayed shorter PFS, indicating that this factor is a predictor but not prognostic marker in the studied population. As the description of the present polymorphism is rather recent $(19,20)$ the studies about its possible influence on survival are scarce. Kawakami et al (20) found that overall survival was significantly longer in low expressor patients treated with oral fluoropyrimidines compared to non-treated, while high expressors did not derive any benefit from chemotherapy. In a study conducted in Spain, Marcuello et al (22) studied 89 patients with metastatic CRC and treated with 5FU. They reported 
significantly longer OS in low expressors and a nearly significant trend $(p=0.07)$ concerning PFS in a univariate analyses, but both parameters achieved p-values of 0.04 in the Cox regression model.

Combination with other variables. Besides SNP, TS expression level and expression pattern, as determined by IHC were found to be closely associated to PFS. The longer time to progression corresponded to patients with tumours showing low TS expression, i.e., weak IHC intensity, and/or cytoplasmic TS expression pattern.

In a preliminary study performed in a series of $77 \mathrm{CRC}$ patients, we failed to find any association between TS expression level and PFS or OS, with the exception of patients with tumours displaying nuclear pattern (7). The significantly longer PFS of patients with weak TS expression found in the present investigation is probably due to the larger size of the sample. In contrast, the shorter time to progression associated to nuclear pattern is confirmed herein.

As described previously, TS expression level and expression pattern were strongly related, the lower TS expression corresponding to patients with cytoplasmic tumours, and these were mostly $\mathrm{C}$ according to SNP classification.

In view of the above results, these three variables are apparently related to PFS. Accordingly, two groups of patients were defined: 'low risk', i.e., those with at least two favourable variables (weak TS expression, cytoplasmic pattern, C SNP) and 'high risk', i.e., at least two unfavourable variables (strong TS expression, nuclear pattern, G SNP). The Kaplan-Meier analysis revealed that PFS was markedly longer for low-risk patients compared to that of high-risk ones. A similar plot was obtained for OS, but statistical significance was not achieved (Fig. 3B). This could be due to the fact that median values were not achieved and, perhaps, could be modified by increasing the size of the studied population and/or the follow-up period.

These results suggest the possibility of designing a method to select patients for subsequent therapies, but further studies in larger populations are needed to confirm the probable combined effect of two or more of the above variables. In addition, a study of TS expression pattern, TS expression levels and SNP in CRC cell lines resistant and sensitive to $5 \mathrm{FU}$ is warranted, not only by our data, but also by reported observations suggesting an association between the intracellular location of TS (nuclear or cytoplasmic) and sensitivity to this drug in other cell lines (36). If these results are confirmed by other investigations, the possible occurrence of doubtful patients would be minimized by assessing 2 out of 3 variables as either favourable or unfavourable to group CRC patients as 'low risk' and 'high risk'.

\section{Acknowledgements}

This study was supported by grants of AstraZeneca Pharmaceuticals (Spain) and the Thematic Network C03/02 (Foundation for Biomedical Research, Hospital Universitario de la Princesa). We thank Ms. Belén Díaz, Ms. María Lozano and Ms. Lourdes Osuna for their technical assistance.

\section{References}

1. Popat S, Matakidou A and Houlston RS: Thymidylate-synthase expression and prognosis in colorectal cancer: a systematic review and meta-analysis. J Clin Oncol 22: 529-536, 2004.
2. Johnston PG, Fisher ER, Rockette HE, Fisher B, Wolmark N, Drake JC, Chabner BA and Allegra C: The role of thymidylate synthase expression in prognosis and outcome of adjuvant chemotherapy in patients with rectal cancer. J Clin Oncol 12: 2640-2647, 1994.

3. Yamachika T, Nakanishi H, Inada K, Tsukamoto T, Kato T, Fokushima $M$, Inoue $M$ and Tatematsu $M$ : A new prognostic factor for colorectal carcinoma, thymidylate synthase, and its therapeutic significance. Cancer 82: 70-77, 1998.

4. Tomiak A, Vincent M, Earle CC, Johnston PG, Kocha W, Taylor M, Maroun J, Eidus L, Whiston F and Stitt L: Thymidylate synthase expression in stage II and III colon cancer: a retrospective review. Am J Clin Oncol 24: 597-602, 2001.

5. Edler D, Glimelius B, Hallstrom M, Jakobsen A, Johnston PG, Magnusson I, Ragnhammar P and Blomgren H: Thymidylate synthase expression in colorectal cancer: a prognostic and predictive marker of benefit from adjuvant fluorouracil-based chemotherapy. J Clin Oncology 20: 1721-1728, 2001.

6. Johnston PG, Benson AB 3rd, Catalano P, Rao MS, O'Dwyer PJ and Allegra CJ: Thymidylate synthase protein expression in primary colorectal cancer: lack of correlation with outcome and response to fluorouracil in metastatic disease sites. J Clin Oncol 5: 815-819, 2003.

7. Fernández-Contreras ME, Jiménez de Ayala B, Velasco A, García de Paredes ML, Majano PL, Palacios J and Gamallo C: Thymidylate synthase expression pattern is a prognostic factor in patients of colorectal cancer treated with 5-fluorouracil. Int J Oncol 25: 877-885, 2004.

8. Horie N, Aiba H, Oguro K, Hojo H and Takeishi K: Functional analysis and DNA polymorphism on the tandemly repeated sequences in the 5'-terminal regulatory region of the human gene for thymidylate synthase. Cell Struct Funct 20: 191-197, 1995.

9. Marsh S, McKay JA, Cassidy J and McLeod HL: Polymorphism in the thymidylate synthase promoter enhancer region in colorectal cancer. Int J Oncol 19: 383-386, 2001.

10. Kawakami K, Ishida Y, Danenberg KD, Omura K, Watanabe G and Danenberg PV: Functional polymorphism of the thymidylate synthase gene in colorectal cancer accompanied by frequent loss of heterozygosis. Jpn J Cancer Res 93: 1221-1229, 2002.

11. Suh KW, Kim JH, Kim YB, Kim JK and Jeong S: Thymidylate synthase gene polymorphism as a prognostic factor for colon cancer. J Gastrointest Surg 9: 336-342, 2005.

12. Marsh S, Collie-Duguid ES, Li T, Liu X and McLeod HL: Ethnic variation in the thymidylate synthase enhancer region polymorphism among Caucasian and Asian populations. Genomics 58: 310-312, 1999.

13. Marsh S, Ameyaw MM, Githang'a J, Indalo A, Ofori-Adjei D and McLeod HL: Novel thymidylate synthase enhancer region alleles in African populations. Hum Mutat 16: 528, 2000.

14. Kawakami K, Salonga D, Park JM, Danenberg KD, Uetake H, Brabender J, Omura K, Watanabe G and Danenberg PV: Different lengths of a polymorphic repeat sequence in the thymidylate synthase gene affect translational efficiency but not its gene expression. Clin Cancer Res 7: 4096-4101, 2001.

15. Kawakami K, Omura K, Kanehira E and Watanabe Y: Polymorphic tandem repeats in the thymidylate synthase gene is associated with its protein expression in human gastrointestinal cancers. Anticancer Res 19: 3249-3252, 1999.

16. Villafranca E, Okruzhnov Y, Dominguez MA, Garcia-Foncillas J, Azinovic I, Martinez E, Illarramendi JJ, Martinez Monge R, Arias F, Salgado E, Angeletti S and Brugarolas A: Polymorphisms of the repeated sequences in the enhancer region of the thymidylate synthase gene promoter may predict downstaging after preoperative chemoradiation in rectal cancer. $\mathbf{J}$ Clin Oncol 19: 1779-1786, 2001.

17. Etienne MC, Chazal M, Laurent-Puig P, Magné N, Rosty C, Formento JL, Francoual M, Formento P, Renée N, Chamorey E, Bourgeon A, Seitz JF, et al: Prognostic value of tumoral thymidylate synthase and p53 in metastatic colorectal cancer patients receiving fluorouracil-based chemotherapy: phenotypic and genotypic analyses. J Clin Oncol 20: 2832-2843, 2002.

18. Jakobsen A, Nielsen JN, Gyldenkerne $\mathrm{N}$ and Lindeberg J: Thymidylate synthase and methylenetetrahydrofolate reductase gene polymorphism in normal tissue as predictors of fluorouracil sensitivity. J Clin Oncol 23: 1365-1369, 2005.

19. Mandola MV, Stoehlmacher J, Muller-Weeks S, Cesarone G, Yu MC, Lenz HJ and Ladner RD: A novel single nucleotide polymorphism within the $5^{\prime}$ tandem repeat polymorphism of the thymidylate synthase gene abolishes USF-1 binding and alters transcriptional activity. Cancer Res 63: 2898-2904, 2003. 
20. Kawakami $\mathrm{K}$ and Watanabe $\mathrm{G}$ : Identification and functional analysis of a single nucleotide polymorphism in the tandem repeat sequence of thymidylate synthase gene. Cancer Res 63: 6004-6007, 2003

21. Yawata A, Kim SR, Miyajima A, Kubo T, Ishida S, Saito Y, Nakajima Y, Katori N, Matsumoto Y, Fukuoka M, Ohno Y, Ozawa S, et al: Polymorphic tandem repeat sequences of the thymidylate synthase gene correlates with cellular-based sensitivity to fluoropyrimidine antitumor agents. Cancer Chemother Pharmacol (In press).

22. Marcuello E, Altes A, Del Rio E, Cesar A, Menoyo A and Baiget M: Single nucleotide polymorphism in the 5 ' tandem repeat sequences of thymidylate synthase gene predicts for response to fluorouracil-based chemotherapy in advanced colorectal cancer patients. Int J Cancer 112: 733-737, 2004.

23. Boland CR, Thibodeau SN, Hamilton SR, Sidransky D, Eshleman JR, Burt RW, Meltzer SJ, Rodriguez-Bigas MA, Fodde R, Ranzani GN and Srivastava S: A National Cancer Institute Workshop on Microsatellite Instability for cancer detection and familial predisposition. Development of international criteria for the determination of microsatellite instability in colorectal cancer. Cancer Res 58: 5248-5257, 1998.

24. Kaplan EL and Meier P: Nonparametric estimation from incomplete observations. J Am Stat Assoc 53: 457-481, 1958.

25. Chen J, Hunter DJ, Stampfer MJ, Kyte C, Chan W, Wetmur J, Mosig R, Selhub J and Ma J: Polymorphism in the thymidylate synthase promoter enhancer region modifies the risk and survival of colorectal cancer. Cancer Epidemiol Biomarkers Prev 13: 2247-2250, 2004.

26. Tsuji T, Hidaka S, Sawai T, Nakagoe T, Yano H, Haseba M, Komatsu H, Shindou H, Fukuoka H, Yoshinaga M, Shibasaki S, Nanashima A, et al: Polymorphism in the thymidylate synthase promoter enhancer region is not an efficacious marker for tumour sensitivity to 5-fluorouracil-based oral adjuvant chemotherapy in colorectal cancer. Clin Cancer Res 9: 3700-3704, 2003.

27. Lecompte T, Ferraz JM, Zinzindohoué F, Loriot MA, Landi B, Tregouet DA, Berger A, Cugnenc PH, Jian R, Beaune P and Laurent-Puig P: Thymidylate synthase gene polymorphism predicts toxicity in colorectal cancer patients receiving 5 fluorouracil-based chemotherapy. Clin Cancer Res 10: 5880-5888, 2004.
28. Pullarkat ST, Stoehlmacher J, Ghaderi V, Xiong YP, Ingles SA, Sherrod A, Warren R, Tsao-Wei D, Groshen S and Lenz HJ: Thymidylate synthase gene polymorphism determines response and toxicity of $5 \mathrm{FU}$ chemotherapy. Pharmacogenomics $\mathrm{J} 1$ : 65-70, 2001 .

29. Iacopetta B, Grieu F, Joseph D and Elsaleh H: A polymorphism in the enhancer region of the thymidylate synthase promoter influences the survival of colorectal cancer patients treated with 5-fluorouracil. Br J Cancer 85: 827-831, 2001.

30. Lee J, Jeong CK, Hong SP, Chong SY, Oh D, Hwang SG, Ahn DH, Kim S, Han JH and Kim NK: Clinical significance of thymidylate synthase and methylenetetrahydrofolate reductase gene polymorphism in Korean patients with gastric cancer. Korean J Gastroenterol 46: 32-38, 2005.

31. Gryfe R, Kim H, Hsieh ET, Aronson MD, Holowaty EJ, Bull SB, Redston $\mathrm{M}$ and Gallinger S: Tumour microsatellite instability and clinical outcome in young patients with colorectal cancer. $\mathrm{N}$ Engl J Med 342: 69-77, 2000.

32. Guerrero D, Balen E, Martínez-Peñuela JM, García-Foncillas J, larrinaga B, Caballero MC, Herrera J and Lera JM: Asociación entre la inestabilidad de microsatélites y las características clínicas y anatomopatológicas en pacientes con cáncer de colon esporádico. Med Clin (Barc) 124: 441-446, 2005.

33. Liang JT, Huang KC, Lai HS, Lee PH, Cheng YM, Hsu HC, Cheng AL, Hsu CH, Yeh $\mathrm{KH}$, Wang SM, Tang C and Chang KJ: High-frequency microsatellite instability predicts better chemosensitivity to high-dose 5-fluorouracil plus leucovorin chemotherapy for stage IV sporadic colorectal cancer after palliative bowel resection. Int J Cancer 101: 519-525, 2002.

34. Gervaz P, Cerottini JP, Bouzourene H, Hahnloser D, Doan CL Benhattar J, Chaubert P, Secic M, Gillet M and Carethers JM: Comparison of microsatellite instability and chromosomal instability in predicting survival of patients with $\mathrm{T} 3 \mathrm{~N} 0$ colorectal cancer. Surgery 131: 190-197, 2002.

35. Ribic CM, Sargent DJ, Moore MJ, Thibodeau SN, French AJ, Goldberg RM, Hamilton SR, Laurent-Puig P, Gryfe R, Shepherd LE, Tu D, Redston M, et al: Tumour microsatelliteinstability status as a predictor of benefit from fluorouracilbased adjuvant chemotherapy for colon cancer. N Engl J Med 349: 247-257 2003.

36. Samsonoff WA, Reston J, McKee M, O'Connor B, Galivan J, Maley $G$ and Maley F: Intracellular location of thymidylate synthase and its state of phosphorilation. J Biol Chem 272: 13281-13285, 1997. 